\title{
Monitoring changes in resident attitudes toward tourism development in small island destinations:
}

\section{What comes next in a post-COVID world?}

Fred R. Schumann (School of Business and Public Administration, University of Guam, schumannf@triton.uog.edu)

\begin{abstract}
Small island destinations with populations of less than one million, typically rely on tourism for economic development and employment generation. Monitoring resident attitudes toward tourism is critical to ensure that government, private sector, and other stakeholders are aware of the perceptions held by residents about the tourism industry and its effects on their quality of life. This paper is a case study of the most recent survey of resident attitudes towards tourism on the Micronesian island of Guam and the use of both quantitative and qualitative methods to measure these perceptions. Results of the survey will be discussed as well as recommendations for destination stakeholders in small islands and rural destinations to prepare for future resident attitude surveys. Special considerations for these less-populated destinations in the post-COVID world will also be examined to ensure that resident perceptions are monitored as a key to maintaining a well-managed tourism destination.
\end{abstract}

\section{Keywords}

tourism, resident attitudes, small islands, post-COVID policy, tourism recovery

\section{Introduction}

\subsection{Sustainable tourism in small islands}

Islands have been popular vacation destinations for the fastgrowing urban populations in major metropolitan areas in the developed world. In particular, small islands, or Small Island Developing States (SIDS), have become popular among international travelers as less-crowded destinations. According to the United Nations [2011], SIDS are a distinct group of developing countries facing specific social, economic, and environmental vulnerabilities, and there are 52 such island nations around the world today.

Small islands in various parts of the world share similar negative and positive characteristics. Some of the negative characteristics include size constraints/small domestic markets; remoteness; instability/natural disasters; and import dependence; while the shared positive characteristics in many cases may be the attractions of natural beauty and unique culture, and the relative ease of implementing domestic policy in restructuring towards service sectors, thus making tourism a viable strategy for economic growth.

Since tourism relies heavily upon the goodwill of the residents, their support is essential for its development, successful operation, and sustainability of the industry in the long term. Monitoring resident attitudes toward tourism development is thus essential to the successful development of the destination.

The sustainable development of tourism in any destination relies on four components of the VICE model [Climpson, 2008] shown in Figure 1.

The four components are described as the following: $\mathrm{V}$ is for visitors of the area, I stands for the service providers and

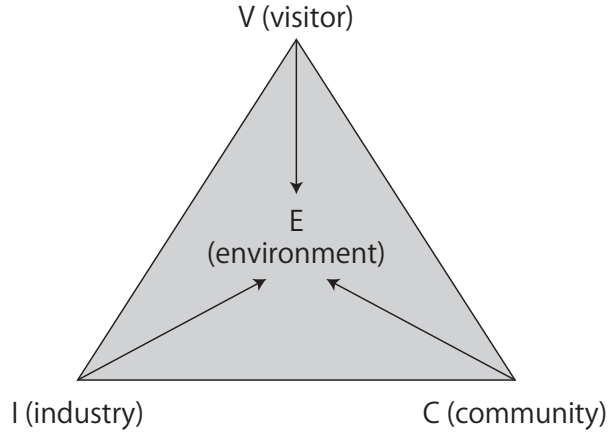

Figure 1: The VICE model

Source: Reproduced by the author based on Climpson [2008].

businesses involved in the tourism industry, $\mathrm{C}$ (community) represents the local community, the population of the area who may or may not be directly related to tourism but living in the area they experience the benefits or harmful effects caused by tourism developments, and by their lifestyles influence the tourism experience offered to visitors. E (environment) includes the natural and the built environment that is available for the visitors, the industry, and the local community, and this environment keeps changing in response to the activities of these groups [Climpson, 2008]. In typical discussions concerning tourism, the focus is often placed on the "I" or the industry, with the business aspect of tourism (hotels, airlines, retail, etc.) taking the center of attention. However, tourism involves more than just the businesses associated with the industry, it is sustainable only if its interests do not conflict with the interests of any of the above four components.

\subsection{Social exchange theory}

Social exchange theory must be discussed here to understand the relationship between community and industry in the VICE 
model. The theory has its roots in sociology and psychology but has great relevance to the tourism industry. This theory was introduced in 1958 by American George Homans who published an article entitled "Social Behavior as Exchange," which is based on the notion that relationships between people are created through a process of cost-benefit analysis [Tulane University, 2018].

Various tourism scholars have published works on social exchange theory and how the theory applies in the field of tourism [Allen et al., 1993; Getz, 1994; Gursoy et al., 2002; Jurowski and Gursoy, 1997; Madrigal, 1993; Perdue et al., 1990; Pizam, 1978; Yoon et al., 2001]. The theory as it applies to tourism indicates that residents are willing to participate in an exchange with tourists if they believe that they are likely to gain benefits without incurring unacceptable costs. If residents perceive that the positive impacts of tourism are greater than the negative impacts, they are inclined to be involved in the exchange and, therefore, endorse future tourism development in their community.

The willingness of residents to participate in an exchange with tourists is an important consideration for the sustainable development of a tourism destination as resident participation is critical to success factors such as enhancing the visitor experience, minimizing leakage, and maintaining cultural authenticity.

\subsection{Residents' perceptions of tourism impacts and attitudes towards tourism policies}

In a study conducted by Brida, Disegna, and Osti [2014], the researchers found that generally the native-born residents in a small mountain community located in the North-East of Italy negatively perceived tourism impacts and were less willing to support any increase in the overall number of tourists. They also learned that residents without a direct economic benefit from tourism and with a negative perception of the sociocultural tourism impacts were less willing to support tourism development.

The relationship between community attachment and tourism impacts is controversial. The authors of the abovementioned study [Brida et al., 2014] also state and provide examples [Harrill and Potts, 2003; Lankford and Howard, 1994; Lankford, 1994; Um and Crompton, 1987] that indicate while studies suggest that the longer an individual resides in a community, the more negative is the attitude towards tourism development, while other studies [Andereck et al., 2005; McGehee and Andereck, 2004; Gursoy et al., 2002; McCool and Martin, 1994] demonstrate that this relation is not true in every situation.

Another study shows that while resident perception research is important, results may differ based on the location, and perhaps even timing, of the study. In Community Scale and Resident Attitudes towards Tourism [Devine et al., 2009], the study explores the role of physical distance from tourism on resident attitudes. In this study, a comparison was made of support for the development of tourism within a person's town of residence versus county. Results showed differences were found across these "community scales" with residents indicating less support for tourism at the, more intimate, town level.

This and other similar studies contradict results of a Balearic Islands study [Bestard and Rossello, 2007], where, in general, results show that the higher the density of tourism, the more favorable people are to tourism development and the less worried they are about its possible negative repercussions. This conclusion can be attributed to the residents' financial and professional dependence on tourism; however, it underlines the fact that while resident attitude surveys are important and should be conducted regularly, results may differ based on the specific destination and the time period.

This study reviews a small island (Guam) case and the steps taken to conduct an island-wide resident attitude survey. Lessons from this case may be applicable to rural destinations, which in many cases, have characteristics similar to small island destinations, with limited populations, limited economic activity, and remoteness from large urban populations.

Destination stakeholders may often be wondering about answers to questions of, "How do we know the way in which residents perceive their relationship with tourism in their community?" and "Do the residents perceive that benefits received from tourism are with or without incurring unacceptable costs?" Resident attitude surveys, especially in small island destinations where residents typically play a larger role either directly or indirectly in the tourism industry, then become an indispensable tool to gauge resident perceptions.

\section{Case study}

Guam, an unincorporated territory of the United States, is the largest and most populous island in the western Pacific region of Micronesia with an estimated population of 170,000. It is located in the northwest Pacific Ocean approximately 6,100 kilometers west of Hawaii, 2,400 kilometers south of Japan, and 3,020 kilometers southeast of South Korea. Guam's economy is primarily supported by tourism, along with military and government spending, thereby underlining the importance of monitoring the well-being of all stakeholders linked to the industry, such as the island's residents.

Guam's destination management organization, Guam Visitors Bureau, had been monitoring how residents perceive tourism in their island community every 4-to-5-year period, but due to various reasons relating to budget constraints and shifting priorities, the surveys did not continue with scheduled frequency. Prior to this case study (2017), the most recent Survey of Tourism Attitudes of Residents (STAR) was last conducted in 2010 .

In 2017, GVB was interested in tracking changes in attitudes recorded in prior surveys and investigating current issues, concerns, and developments within the tourism industry. Questions from prior surveys were to be included to allow for comparisons to track changes, with more current issues added for new insights. To accomplish this the project comprised of three 
elements, a qualitative assessment, quantitative assessment, and finally a drivers analysis.

The qualitative assessment was the first phase of the project and involved focus group meetings. Two focus groups were convened to explore issues important to residents today. The first group was comprised of "cultural stakeholders" to discuss issues about tourism that may be affecting the culture of Guam. The second group was among local private and public stakeholders representing local government and business interests. These two groups represented different segments of the community and provided in-depth information concerning tourism and the quality of life for residents. The focus groups also provided background data to identify more current issues of concern to residents that could be further researched in the quantitative assessment in the form of new survey questions.

The quantitative assessment was conducted utilizing a telephone survey. More than 1,200 residents inclusive of 600 Chamorros (the indigenous people of the Mariana Islands of which Guam is the largest and southernmost of the island chain) were interviewed over a four-week period. The survey quantitatively assessed issues identified through the focus groups and tracked changes in items of importance to GVB from prior surveys.

Residents surveyed were defined as those with over 2 consecutive years of residency on the island of Guam and over the age of 18 . Survey respondents were proportionately representative of all residents at $\pm 3 \%$ and representative of residents of villages in the north (Yigo, Tamuning, Harmon, Tumon, and Dededo), the central region (Agana, Agana Heights, Asan, Barrigada, Chalan Pago/Ordot, Mangilao, Mongmong-Toto-
Maite, Piti, Sinajana) and the south (Agat, Santa Rita, Umatac, Merizo, Inarajan/Malojloj, Talofofo, Yona) with a $\pm 6 \%$ level of accuracy. The entire data set had a $95 \%$ confidence level.

The third element of the project, the drivers analysis, was conducted to identify what is most important in shaping the attitudes of residents. The quantitative survey and its results provided the means to identify what is most important in shaping the attitudes of residents, whether positive or negative, regarding tourism. For the drivers analysis, a two-stage regression analysis was conducted, and key drivers of local attitudes were identified.

\section{Findings and discussion}

3.1 Overall results and benefits of the resident attitude survey

For the purpose of this paper, we can examine the overall measures from the 2017 telephone survey and discuss the importance of the continual replication of the survey to compare results and identify trends.

Prior to conducting the telephone surveys, the first element of the project, the focus groups, convened to explore current tourism-related issues among the two groups and to gain indepth information concerning tourism and quality of life. The qualitative data was compiled in a report and the data was also used to include additional questions in the second element, the questionnaire for a quantitative assessment.

Results of the 2017 telephone survey show that the majority of residents view tourism favorably as an industry in Guam and that residents also have a positive outlook for the growth of Guam's economy [Guam Visitors Bureau, 2017]. This survey
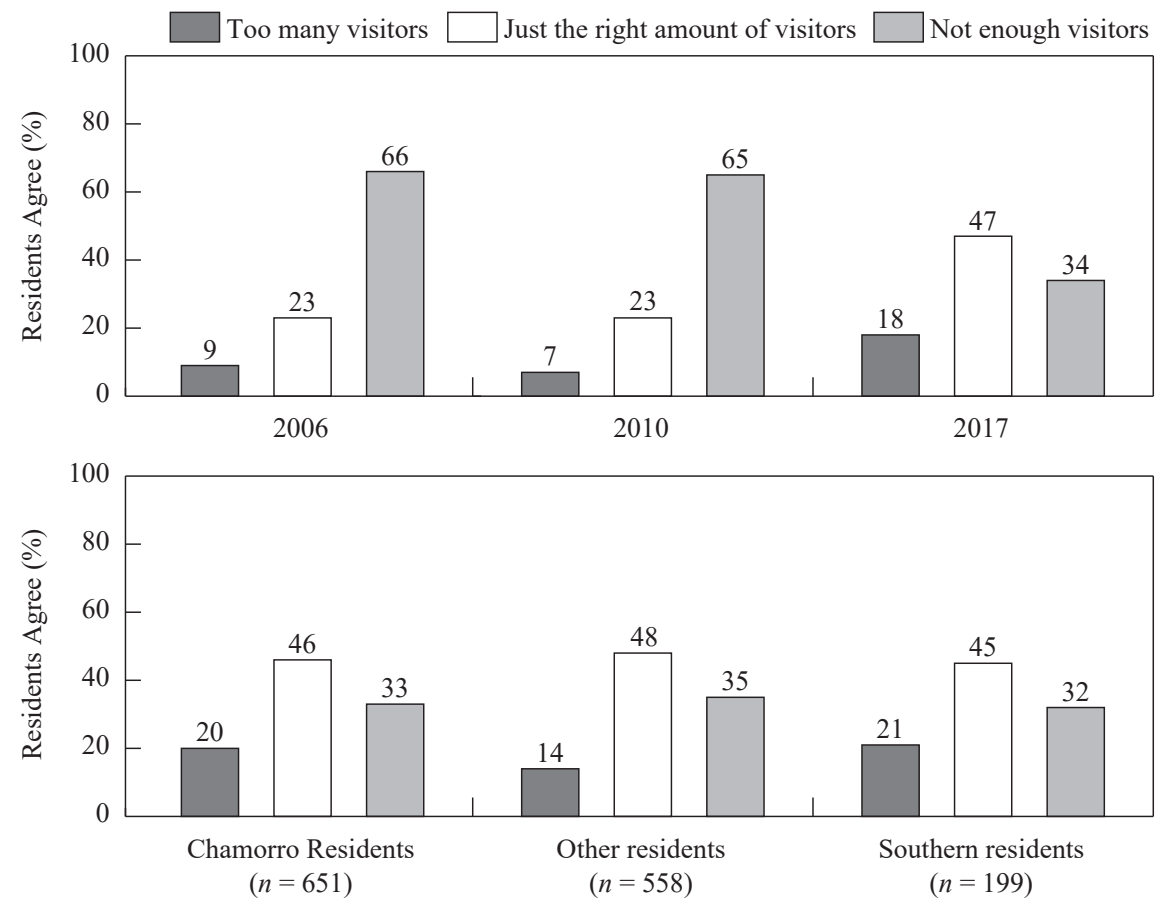

Figure 2: Residents' perception of tourism (Quantity)

Source: Reproduced by the author based on Guam Visitors Bureau [2017]. 
also indicated a greater tendency than in previous years to state that Guam has too many visitors (see Figure 2).

Some other key findings from this survey indicate that residents perceive there is a balance between the benefits from tourism and the preservation of culture, environment, and quality of life; tourism helps to preserve the Chamorro culture and language (see Figure 3); the perception concerning the way tourism industry workers are perceived to be treated by visitors show a negative trend, and results show an increase in the proportion of residents agreeing with the statement that Guam has too much crime.

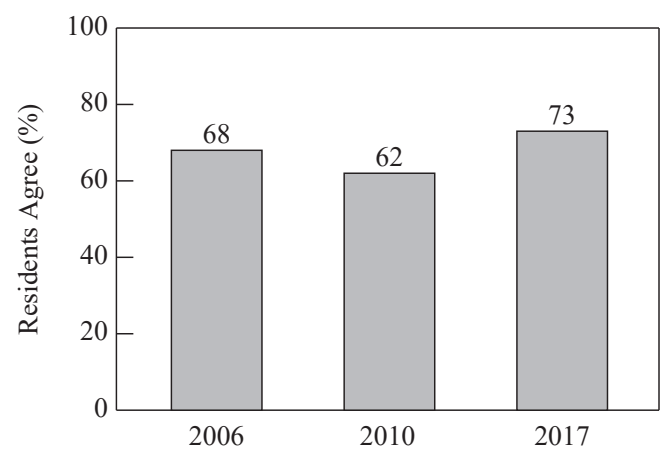

Figure 3: Residents' perception of tourism and culture $(N=$ 1,257)

Source: Reproduced by the author based on Guam Visitors Bureau [2017].

The 2017 survey provided a more current insight into how residents perceive jobs in the tourism industry, which of course is important to monitor in a destination like Guam where tourism is the leading industry for employment. Results showed that most residents agree that tourism creates many well-paying jobs and that there is a marked increase in residents agreeing that most industry managers are from Guam these days. However, there was an increase in the perception that most tourism jobs "don't offer much chance for advancement." Based on these results, stakeholders can conduct further research to determine how these perceptions can be realistically improved.

Finally, the third element of the project, the drivers analysis, was used to identify what is most important in shaping the attitudes of residents regarding tourism. The findings indicated that the following two factors were most important in shaping residents' attitudes: Creates Jobs and Opportunities (82\%) and Depiction of Chamorro Culture (16\%). These results give Guam Visitors Bureau a clear view of what factors residents consider, at the time of this particular survey, when shaping their attitudes about the tourism industry in Guam.

The benefits of conducting resident attitude surveys have already been presented in this paper, but a benefit that has yet to be mentioned is another function of the process. That is, the resident attitude survey can also serve as the performance evaluation or "report card" for the destination management organizations, or in this case, of Guam Visitors Bureau. In the Guam Visitors Bureau survey project, various events, campaigns, and other areas of the bureau's involvement were presented in both the focus groups and telephone interviews to gather information from participants to gather their perceptions on the effectiveness of these efforts. In the focus groups, privatepublic sector projects, videos, and images were presented to collect feedback from participants, while during the telephone surveys, events and promotions were mentioned to gather residents' knowledge about such efforts. Results may be useful in assisting with the selection of priority projects with the limited funding available for the bureau's marketing efforts.

Some other uses of the data from resident attitude surveys include new opportunities to extract more detailed data with further research utilizing feedback from questions about quality of life improvements, both from the focus group discussions and the telephone survey. By reviewing the most recent results and learning about new issues and trends concerning tourism in a destination, stakeholders can work toward continuous improvement in an enhanced survey for more targeted results.

\subsection{Tourism attitudes of residents and COVID}

The tourism industry is not necessarily a highly predictable one. Some tourism trends have lasting power, while others may shift due to unexpected global events. Events such as 9/11, the Global Recession resulting from the 2008 financial crisis, and disasters like the 2004 Indian Ocean earthquake and tsunami and Japan's 2011 Triple Disaster can have major, and often unpredicted, impacts on travel habits and trends.

On 30 January 2020, the Director-General of the World Health Organization (WHO) declared the outbreak of COVID-19 to be a Public Health Emergency of International Concern and issued a set of Temporary Recommendations [World Health Organization, 2020]. At the time, WHO did not recommend any travel or trade restrictions based on the current information available, but the impacts of this event were felt globally and tourism, particularly international tourism, was affected tremendously.

Destination stakeholders must now be wondering about more current answers to questions concerning the relationship between tourism and their community. Some of these questions for small island destinations include: How has COVID affected tourism attitudes of residents? What steps should be taken now that tourism has changed in many destinations, and particularly in small islands where it has virtually come to a standstill? How can the industry respond in a measured and consistent way, proportionate to the public health threat perceived by residents?

The Organization for Economic Co-operation and Development (OECD), the intergovernmental economic organization with 37 member countries, published a report entitled, Rebuilding tourism for the future: COVID-19 policy response and recovery [OECD, 2020]. The report states that while the outlook for tourism economy recovery remains highly uncertain, there are potential long-lasting tourism policy implications to consider. (see Table 1) 
Table 1: Tourism in a post-COVID world?: Potential longlasting tourism policy implications

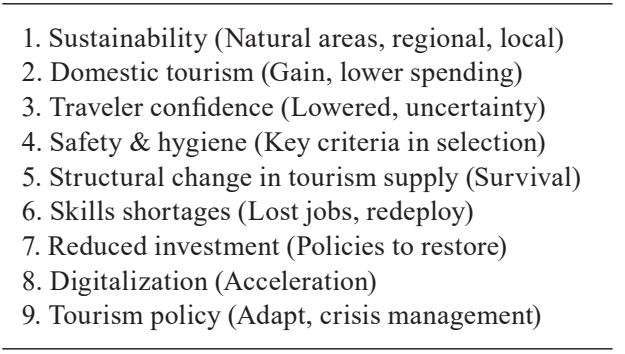

Source: OECD [2020]. Rebuilding tourism for the future.

These nine potential long-lasting tourism policy implications are important considerations for destinations planning for tourism recovery. The nine policy implications and how they may be relevant to small island destinations will be noted below with potential relevant questions for destination stakeholders in italics for each of the nine implications.

- Sustainability:

Natural areas, regional and local destinations are expected to drive the recovery, consequently, shorter travels will result in a lower environmental impact of tourism. Will this drive demand for travel to small island destinations? Should islands take a more regional approach in recovery efforts?

- Domestic tourism:

Domestic travel is expected to gain in shares and flows, as people prefer to stay local. Domestic tourists are often more price-sensitive and tend to have lower spending patterns. How will this affect travel to islands in remote destinations?

- Traveler confidence:

Confidence is expected to be lowered due to the ongoing uncertainty. This may lead to a decline in tourism consumption that might continue well long after the initial shock. Should this be more of a concern for less populated destinations and those with less developed infrastructure?

- Safety and hygiene:

These are becoming key factors to select destinations and tourism activities. What are the perceptions held by potential visitors from major source markets about the level of safety and hygiene at our particular destination? How does this match up with our residents' perception of adequate levels of safety and hygiene?

- Structural change in tourism supply:

This is expected across the ecosystem. Not all businesses will survive the crisis and capacity in the sector is likely to be reduced for a period. How prepared are we to address the lower capacity and the resulting changes in the business environment?

- Skills shortages:

The skills shortage that already existed in many tourism destinations may be exacerbated, as many jobs are lost and workers will redeploy to different sectors. What efforts can we take to continue developing skills and keep the industry attractive to residents?

- Reduced investment:

This will call for active policies to restore investment in the tourism sector with the aim of promoting a sustainable recovery of the sector. How do residents feel about the restoration of investment in the industry?

- Digitalization:

The digitalization of services that was already in place in tourism services prior to COVID is expected to continue to accelerate, including a higher use of automation, contactless payments, and services, virtual experiences, etc. Are we properly equipped to address the technology needs with new expectations from tourists?

- Tourism policy:

The ability to adapt faster to changes of policy focus will be critical and crisis management will be a particular area of focus. Do residents working public and private sector agencies understand the need for greater integration of services to meet new challenges? Is streamlining public-private interfaces through a tourism nerve center feasible and/or desired by residents?

\section{Conclusion and recommendations}

This paper presented through Guam's case study the importance of monitoring perceptions of residents of small island destinations to identify new issues and trends that are critical to maintaining a sustainable tourism destination. It emphasized the importance of residents as supporters of tourism due to the large role they play either directly or indirectly in the experience of the visitors.

The methodology used in the Guam case study and the general results of the STAR survey were shared to review how conducting scheduled resident attitude surveys can result in various benefits to the destination. These include the ability to identify new issues concerning tourism, trends in resident attitudes as compared with previous surveys, and the opportunity to use the survey tool as a way to evaluate the performance of the destination management organization, as it did for Guam Visitors Bureau. In addition, going back to the VICE model and Social Exchange Theory, this paper stressed the importance of monitoring resident attitudes toward tourism and maintaining community support for the tourism industry to succeed, as the interaction with people in the community plays a huge role in the experience of the tourist.

An important lesson from this case study is that resident attitudes of tourism can change over time as seen in the comparisons of responses to the same questions taken from different years that the survey was conducted. With various events occurring at the local, national, or regional level, resident attitudes toward tourism can easily change due to shifting priorities or other reasons. With a global event, such as the COVID pandemic, we can assume that tourism, as small island residents knew it prior to COVID, is being reexamined and 
reevaluated as a primary industry.

A recommendation to consider for small island destination management organization stakeholders is to conduct a resident attitude survey before fully opening to tourists to gauge how residents perceive the place of tourism in their community. Managers of the survey will also benefit from examining OECD's nine potential long-lasting tourism policy implications and introducing appropriate questions related to these implications when designing the survey model.

As people take steps toward the Post-COVID era of travel, words such as "regenerative," "resilience," and "reimagined" are being associated with the new form of tourism that will emerge. Reimagined tourism, for example, can be a better tourism model, one with new definitions for success and growth. By conducting well-managed resident attitude surveys with the integration of the possible long-lasting policy implications of COVID, stakeholders may be a step closer to identifying positively impactful reimagined tourism opportunities for their particular destination to benefit both residents and tourists in the long run.

\section{References}

Allen, L. R., Hafer, H. R., Long, P. T. \& Perdue, R. R. (1993). Rural residents attitudes toward recreation and tourism development. Journal of Travel Research, Vol. 31, No. 4, 2733.

Andereck, K. L., Valentine, K. M., Knopf, R. C. and Vogt, C. A. (2005). Residents' perceptions of community tourism impacts. Annals of Tourism Research, Vol. 32, 1056-1076.

Bestard, A. B. \& Rossello, J. R. (2007). Attitudes toward tourism and tourism congestion. Region et Developpement, Vol. 25, 193-207.

Brida, J. G., Disegna, M., \& Osti, L. (2014). Residents' perceptions of tourism impacts and attitudes towards tourism policies. Tourismos: An International Multidisciplinary Journal of Tourism, Vol. 9, No. 1, 37-71.

Climpson, A. (2008). Sustainable destination management: The VICE model. Tourism Insight (Retrieved March 24, 2021 from http://www.insights.org.uk/).

Devine, J., Gabe, T., and Bell, K. P. (2009). Community scale and resident attitudes towards tourism. Journal of Regional Analysis and Policy, Vol. 39, No. 1, 1-12.

Getz, D. (1994). Residents' attitudes towards tourism: A longitudinal study in Spey Valley, Scotland. Tourism Management, Vol. 15, No. 4, 247-258.

Guam Visitors Bureau (2017). Survey of tourism attitudes of residents. Market Research \& Development, Guam Visitors Bureau.

Gursoy, D., Jurowski, C., and Uysal, M. (2002). Resident attitudes: A structural modeling approach. Annals of Tourism Research, Vol. 29, No. 1, 79-105.

Harrill, R. and Potts, T. D. (2003). Tourism planning in historic districts: Attitudes toward tourism development in Charleston. Journal of the American Planning Association, Vol. 69,
No. 3, 233-244.

Jurowski, C. and Gursoy, D. (2004). Distance effects on residents' attitudes toward tourism. Annals of Tourism Research, Vol. 31, No. 2, 296-304.

Lankford, S. (1994). Attitudes and perceptions toward tourism and rural regional development. Journal of Travel Research, Vol. 32, 35-43.

Lankford, S. V. and Howard, D. R. (1994). Developing a tourism attitude impact scale. Annals of Tourism Research, Vol. 24, No. 1, 121-139.

Madrigal, R. (1993). A tale of tourism in two cities. Annals of Tourism Research, Vol. 20, No. 2, 336-353.

McCool, S. and Martin, S. (1994). Community attachment and attitudes toward tourism development. Journal of Travel Research, Vol. 32, No. 3, 29- 34.

McGehee, N. and Andereck, K. (2004). Factors predicting rural residents' support of tourism. Journal of Travel Research, Vol. 43, 131-140.

OECD (2020). Rebuilding tourism for the future: COVID-19 policy response and recovery. OECD Policy Responses to Coronavirus (COVID-19) (Retrieved March 24, 2021 from http://www.oecd.org/coronavirus/policy-responses/rebuilding-tourism-for-the-future-covid-19-policy-responses-andrecovery-bced9859/).

Perdue, R. R., Long, P. T., and Allen, L. (1990). Resident support for tourism development. Annals of Tourism Research, Vol. 17, No. 4, 586-599.

Pizam, A. (1978). Tourism's impacts: The social costs to the destination community as perceived by its residents. Journal of Travel Research, Vol. 16, No. 4, 8-12.

Tulane University (2018). What is social exchange theory? School of Social Work (Retrieved March 24, 2021 from https://socialwork.tulane.edu/blog/social-exchange-theory).

Um, S. \& Crompton, J. L. (1987). Measuring resident's attachment levels in a host community. Journal of Travel Research, Vol. 26, No. 2, 27-29.

United Nations (2011). Small island developing states: Small islands big(er) stakes. Office of the High Representative for the Least Developed Countries, Landlocked Developing Countries and Small Island Developing States (UN-OHRLLS).

World Health Organization (2020). A joint statement on tourism and COVID-19: UNWTO and WHO call for responsibility and coordination (Retrieved March 24, 2021 from https:/www.who.int/news/item/27-02-2020-a-jointstatement-on-tourism-and-covid-19---unwto-and-who-callfor-responsibility-and-coordination\#: : text $=\mathrm{On} \% 2030 \% 20$ January\%202020\%2C,set\%20of\%20Temporary\%20Recommendations).

Yoon, Y., Gursoy, D., and Chen, J. (2001). Validating a tourism development theory with structural equation modeling. Tourism Management, 22, 363-372.

(Received March 24, 2021; accepted April 21, 2021) 